\section{Shape the Future of MRS}

MRS is looking for you! The Materials Research Society, as I hope you have begun to see, is changing. As society realizes that materials are a pivotal part of solutions to the challenges of issues such as "green" energy, environmental sustainability, and clean water. Interest in MRS and its activities is consequently increasing. In response, MRS is expanding its meetings, its publications, and its outreach activities to be able to serve the growing needs of its members and to be a facilitator of a broad public dialogue on the nature and benefits of materials research. The amount of effort possible from the existing volunteers and Headquarters staff is finite. So, if MRS is to continue to expand its service to the community through exciting new initiatives, more volunteers are needed. . . LIKE YOU!!!

Following is a list of some of the opportunities:

- Materials Research News: As part of the publications initiative, MRS is investigating ways to deliver materials research news, and needs helpparticularly volunteers excited about Web 2.0, social media, and mobile device apps. Science writers are also needed to identify and write up items of interest to the community.

- Technical Program Committee and Its Subcommittees: Meetings are a key part of what makes MRS work. As the scope of meetings increases, MRS needs more help in planning, quality evaluations, and meetings strategic planning.

- Awards Committee: Awards are a key way that MRS recognizes outstanding

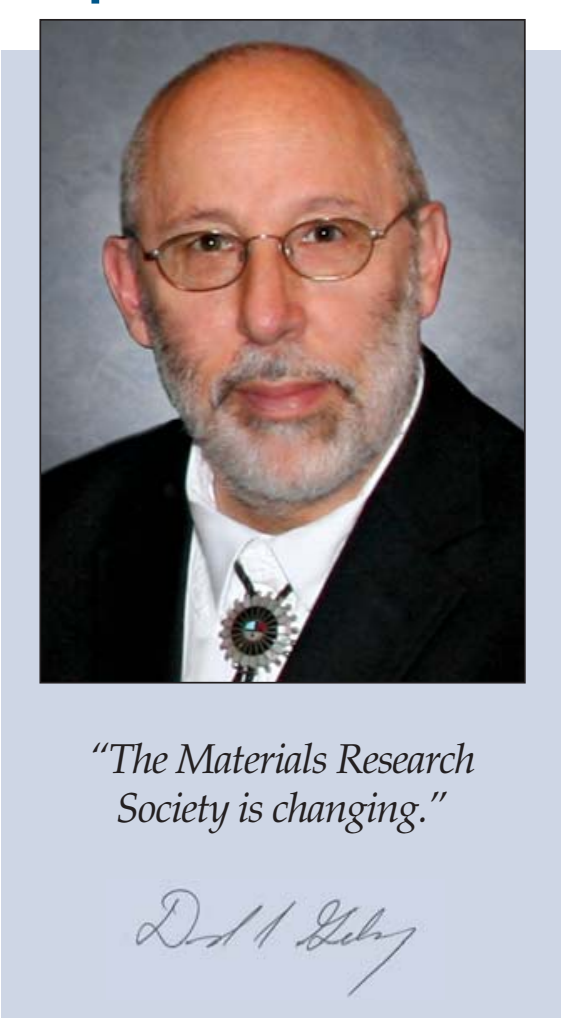

researchers for their contributions to materials science. MRS needs your help as we investigate new awards, look at the existing ones, and assess the needs of the materials community.

- Publications: MRS is looking for volunteers who could serve on the development teams and ultimately editorial boards of new journals focused on, among others, the materials aspects of biomaterials, energy, and the environ- ment. If you see a significant gap in the publications landscape for materials we encourage you to pursue it.

- Academic Affairs: MRS wishes to expand its educational services. We need volunteers who are passionate about education and student issues (nationally and internationally). This includes participation in accreditation activities (such as ABET for engineering) as well as broader education programs spanning the interdisciplinary nature of materials research.

- Education and Outreach: MRS is looking for help to develop the next generation of MRS outreach programs for the education community, ages $6-17$, and the general public. Volunteers are needed who have a passion for communicating the power and wonder of materials research to everyone.

MRS needs you! If you think you are the "right stuff," please contact Kathy D’Biagio atdbiagio@mrs.org. Not only will you find that most of these positions are fun, but you will meet a diverse set of materials researchers with shared values. . . and it's good for your career.

In addition, if you have an inspiration about something MRS could do better or differently to address the areas listed or those identified in our strategic goals, we are interested-send your ideas to dbiagio@mrs.org, as well. Many of the best ideas in MRS started because of the passion of members who took the time to advocate for their ideas.

DAVID S. GINLEY 2010 MRS President

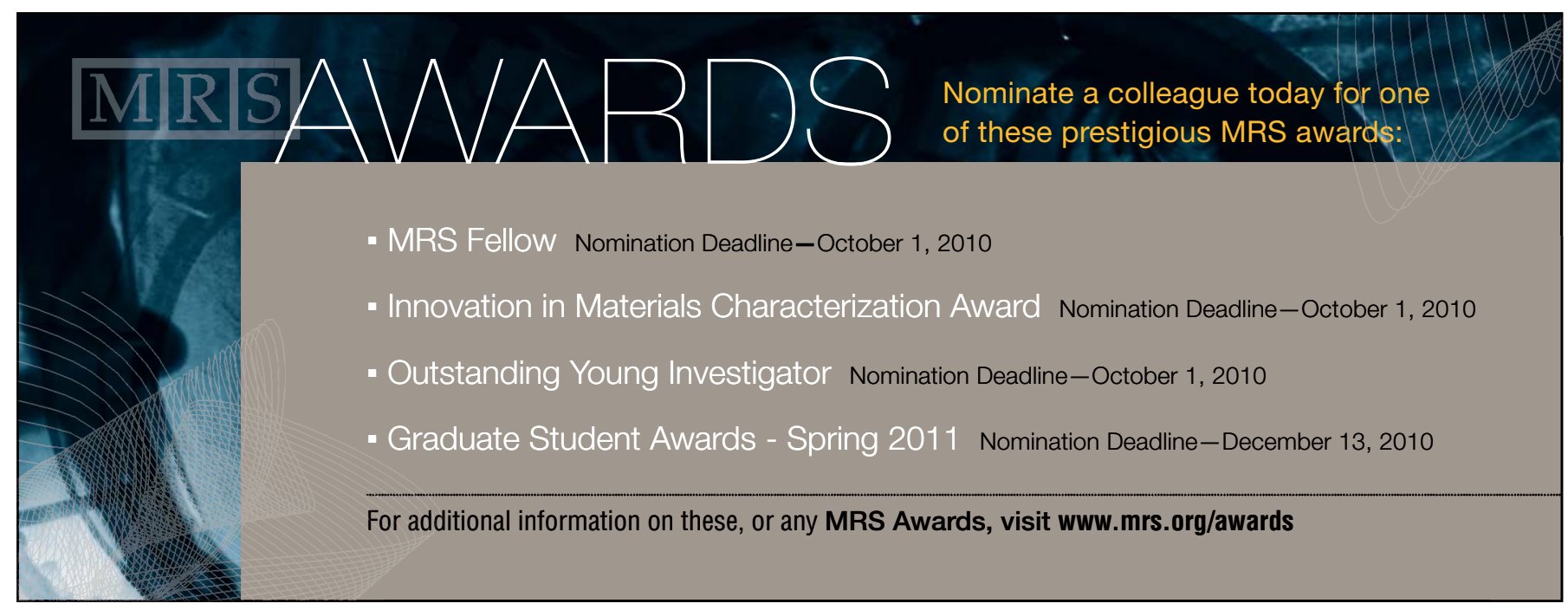

